\title{
A Walk in the Woods: Changing Student Attitudes toward Amphibians and Reptiles
}

\author{
Bradley R. Reynolds, Team Salamander, Thomas P. Wilson* \\ Department of Biology, Geology, and Environmental Science, University of Tennessee at Chattanooga, Chattanooga, USA \\ Email: ${ }^{\star}$ Thomas-Wilson@utc.edu
}

How to cite this paper: Reynolds, B. R., Salamander, T., \& Wilson, T. P. (2018). A Walk in the Woods: Changing Student Attitudes toward Amphibians and Reptiles. Creative Education, 9, 182-191. https://doi.org/10.4236/ce.2018.92014

Received: December 19, 2017

Accepted: February 10, 2018

Published: February 13, 2018

Copyright ( $\odot 2018$ by authors and Scientific Research Publishing Inc. This work is licensed under the Creative Commons Attribution-NonCommercial International License (CC BY-NC 4.0). http://creativecommons.org/licenses/by-nc/4.0/ (c) (i) \& Open Access

\begin{abstract}
In an attempt to develop an appreciation for amphibians and reptiles among non-science majors, we integrated field work and hands-on herpetology into our instruction of a non-laboratory lecture course. We used a pre-test/ post-test survey and paired t-tests to evaluate student empathy for a variety of organisms, including salamanders and snakes. We likewise used reflective journals to monitor student attitudes toward amphibians and reptiles throughout the field experience and structured interviews to more fully explore emerging themes. Quantitatively, student empathy towards salamanders, the one organism to which they were routinely exposed, was greater after completion of the field experience. Likewise, several students expressed a greater appreciation for and comfort with amphibians and reptiles, as measured through reflective journaling and qualitative interviews. These findings suggest that actively engaging students in the field and exposing them to amphibian and reptile conservation may enhance the appreciation of these species, alleviate or lessen herpetophobia, and promote environmental protection. The broader impacts of these findings have clear ties to the management of non-game biodiversity and conservation implications for the global environment. Furthermore, natural resource managers and teachers in higher education should carefully integrate experiential education and reflective practice into their programs to enhance environmental awareness among their students, along with a desire to conserve non-game biodiversity, including amphibians and reptiles.
\end{abstract}

\section{Keywords}

Environmental Education, Public Environmental Awareness, Experiential Learning, Reflective Practice, Design Process Thinking, Hands-On Herpetology, Salamanders 


\section{Introduction}

Some people dislike amphibians and reptiles (Gibbons, 1983). Certain individuals even possess an irrational fear of herpetofauna (APA, 2013). For some, the fear of amphibians and reptiles is transient and fleeting; for those with true herpetophobia; the fear of amphibians and reptiles is panic-inducing and even crippling (APA, 2013). True herpetophobia is marked by the phobic object or phobic stimulus provoking immediate fear or anxiety (APA, 2013). The phobic object or situation is therefore actively avoided, or at best, endured (APA, 2013). All the while, the fear or anxiety experienced is excessive in light of the actual danger posed by the perceived threat (APA, 2013). Snakes, for example, are largely harmless (Schneider et al., 2001). Even so, people tend to loathe, fear, and even persecute snakes (Alves et al., 2014; Prokop, Özel, \& Uşak, 2009), venomous and non-venomous alike, and fear of snakes remains humankind's most common phobia (Isbell, 2009). During fall of 2012, in an attempt to combat superficial herpetophobia and develop an appreciation for amphibians and reptiles among non-science majors, we integrated field work and hands-on herpetology (Schneider et al., 2001) into our instruction of a 1000-level non-laboratory lecture course entitled Conservation of Biodiversity.

As researchers, we did not seek to diagnose or document clinical herpetophobia in the study participants. Instead, we took note when the students reported a fear or dislike of herpetofauna. We then sought to alleviate that fear and produce a greater appreciation for amphibians and reptiles through simple exposure, by actively engaging the students in a real-world amphibian and reptile monitoring project.

A search of the literature reveals that reptiles and amphibians have been used as study organisms by other researchers for the purposes of science education and that such projects have the potential to positively impact student attitudes toward herpetofauna, although more investigation is needed. An attitude can be defined as a belief-based feeling that influences one's response toward an object or entity (Tomažič, 2008). Tomasek, Matthews, and Hall (2005) describe how to sample for reptiles and amphibians using a drift fence array and pitfall traps, and note that through amphibian and reptile sampling, student attitudes are altered, with the students becoming more environmentally aware and more appreciative of amphibians and reptiles (Tomasek et al., 2005). Ballouard, Provost, Barre, and Bonnet (2012) assert that field trips that incorporate hands-on experiences with animals are more impactful when it comes to altering student attitudes than the modern-day trend of providing virtual experiences. The authors used a single snake-catching field trip and some simple snake handling to positively impact the attitudes of 500 school children. The hands-on nature of the experience was key in improving student attitude toward a historically "unpopular organism" (Ballouard et al., 2012). The authors' assertion that the hands-on nature of the experience was crucial echoes Morgan and Gramann (1989), who found that enhanced knowledge of snakes alone failed to improve children's attitudes to- 
ward snakes, but physical contact with snakes did produce improvement. Tomažič (2008) focused not on snakes, but on frogs and salamanders, and found that after a 45-minute lesson utilizing live amphibians, student attitudes toward the animals were positively impacted. This was especially true for those students that already had some kind of direct experience with the animals. Lectures that failed to utilize live animals produced a lesser response. Defina (1986) likewise suggests that amphibians and reptiles can be used as study organisms for science education and found that working with herpetofauna in the field is "an educational experience which ... has more personal impact than textbook descriptions" (p. 82). In short, factual knowledge alone is insufficient when it comes to reducing fear (Tomažič, 2011). Direct exposure, or some combination of education and exposure, is likely more effective (Makashvili, Kaishauri, \& Azmaiparashvili, 2014).

Direct interaction with live animals appears to be important as far as producing an attitude change (Morgan \& Gramann, 1989; Ballouard et al., 2012). This is consistent with Kolb's Experiential Learning Cycle, which consists of four stages (Kolb, 1984). In the Concrete Experience stage, learners actively and directly engage in an activity or experience a phenomenon or object (Kolb, 1984). In the Reflective Observation stage, learners reflect on the activity or experience (Kolb, 1984). The Abstract Conceptualization stage follows, during which learners form abstract models related to the activity or experience (Kolb, 1984). Finally, in the Active Experimentation stage, learners test out their newfound ideas and attitudes in new or novel situations (Kolb, 1984). The current study expanded upon Kolb's learning theory and used hands-on herpetology (Schneider et al., 2001) to produce in non-science majors a greater appreciation for amphibians and reptiles. Specifically, our objectives were: 1) to foster the development of empathy for amphibians and reptiles, where empathy is the ability to identify with and understand the thoughts and feelings and worth of another, 2) to battle superficial herpetophobia among non-science majors, 3) to foster the development of solid critical thinking skills in students through reflective practice, and 4) to provide support for a long-term amphibian and reptile monitoring project at a local wetland. In going to the woods and in handling salamanders and frogs, we hypothesized that the participants would develop a greater appreciation for amphibians and reptiles, and in some cases, overcome superficial herpetophobia.

\section{Materials and Methods}

The project took place at the University of Tennessee at Chattanooga (UTC) Wetland (LT6) located just off of Highway 58 behind Chattanooga Central High School, approximately 30 minutes northeast of downtown Chattanooga and the main UTC campus. This 10-acre wetland sits on 91-acres of mixed hardwood forest, once part of the 6000-plus acre Volunteer Army Ammunition Plant (VAAP), a Department of Defense installation (Wilson, 2012; Wilson et al., 2015; Wilson et al., 2017). This wetland was donated to UTC by the federal govern- 
ment for research and instructional purposes (Wilson, 2012; Wilson et al., 2015; Wilson et al., 2017).

During fall 2012, Conservation of Biodiversity students could attend lecture, assist with a rigorous real-life amphibian and reptile monitoring project, and in lieu of a traditional final, keep a reflective journal. Forty-two non-science majors (approximately 44\% male and 56\% female) hailing from a variety of disciplines (with ages generally ranging between 18 and 24 years) opted to assist with amphibian/reptile monitoring in the field. It should be noted that while a larger sample size would have been preferable, this course of action was not practical given certain field limitations making it difficult to accommodate larger groups (Hawkins, 2014). However, we made every effort to meet our projected sample size requirements based on statistical power tests. Specifically, our sample population was 42 students. Striving for a 95\% confidence interval (5\% error), we needed 38 students to successfully complete the field experience and associated surveys (Hawkins, 2014). Also, letting students volunteer may have produced some selection bias which of course hinders our ability to generalize, but all the same, this was the soundest approach, given that animal safety was paramount (Henry, 1990). In short, a probability sampling method was just not practical, because when animal lives are at stake, participant cooperation and commitment is crucial (Fink, 1995). The 42 non-science majors that participated were expected to collect data in support of a real-life conservation-based research project. The researcher in charge of this project has been monitoring Abystomatids and other herpetofauna at LT6 since 2004, with a carefully-installed drift fence array and a series of pitfall and funnel traps, as a means of determining whether or not human development in adjacent areas is adversely impacting the amphibian and reptile life present.

For the current assessment, the 42 students were divided into five groups of approximately eight individuals. Each group was given instructions and training on Friday afternoon. The students learned how to properly identify, sex, measure, weigh, and release any captured amphibians and reptiles. They also learned how to record biological data. Each group was then taken to LT6 to assist with amphibian and reptile monitoring across three successive Saturdays (the project ran for a total of 15 weeks). During fall of 2012, the project focused mostly on the movements and migrations of the marbled salamander, Ambystoma opacum.

A pre-test/post-test Empathy Survey, which had been carefully evaluated for validity by a team of experienced social scientists, was utilized before and after each group's three-week experience (Hill \& Lewicki, 2006; Green \& Salkind, 2008). This survey measured the ability to feel empathy for nonhuman life, specifically, a tree, a bird, a salamander, a snake, a raccoon, and a squirrel, on a 1 to 5 scale with 1 being low and 5 being high. Data were analyzed using paired-samples $t$-tests in SPSS 17.0. Student surveys were paired using the UTC student ID, with alpha values set at the 0.05 level (Hill \& Lewicki, 2006; Green \& 
Salkind, 2008).

Students were expected to make a minimum of seven entries in their journals over each group's three-week period. Four entries were in response to writing prompts given by the researchers. Three entries were open-ended. Like Plack et al. (2004), a Critical Reflection Rubric was used to evaluate the reflective journals at the end of the field experience. This Critical Reflection Rubric took advantage of the same nine elements utilized by Plack et al. (2004): reflection in action, reflection on action, reflection for action, content, process, premise, returns to experience, attends to feelings, and reevaluates, plus an Overall Level of Reflection Category. All journals were read by the primary researcher in their entirety. The journals where true critical reflection had taken place, as determined by the Critical Reflection Rubric, were noted. Fifteen of these critical reflection journals were then randomly selected and examined even more thoroughly by the primary researcher, with recurring themes color coded and organized.

Five of the subjects that had critically reflected were then purposively selected to participate in qualitative interviews with the primary researcher; note-taking was used to record subject responses. Each interview lasted approximately 30 minutes. The intent was to investigate and document with rich description any recurring themes and/or attitude changes in the participants.

As for the Interview Protocol, the interview questions revolved primarily around the role of the instructor, the impact of the hands-on outdoor experience, and general student attitude toward amphibians and reptiles. The interview questions were dictated by the results of the surveys and by the various journal entries made; this is consistent with an explanatory sequential design (Creswell, 2007).

\section{Results}

For the 38 individuals that had correctly filled out the pre-test/post-test Empathy Survey $(\mathrm{n}=38)$, the ability to feel empathy for salamanders had increased in a statistically significant way $(M=3.78, S D=0.90), t(38)=2.321, p=0.026)$, although it had not increased significantly for any other organism (although empathy for snakes did approach significance at the 0.10 level). The $95 \%$ confidence interval for the mean difference was 0.04 to 0.64 (see Table 1).

As for the 42 journals, 22 showed evidence of Critical Reflection, 14 showed evidence of Reflection, and 6 showed No Reflection. Recurring journal themes included a greater appreciation of amphibians and reptiles. Some individuals commented on the intrinsic value and inherent worth of amphibians and reptiles. Others stressed the ecological roles played by herpetofauna. Some seemed more focused on preserving amphibians and reptiles for the benefit of future generations.

Confronting and overcoming nervousness and a fear of amphibians and reptiles was the most notable recurring journal theme. Students initially expressed their discomfort and fear, before arriving at the realization that such discomfort 
Table 1. Paired-samples $t$-test results for empathy for field participants.

\begin{tabular}{cccccccc}
\hline & $\begin{array}{c}\text { Pre-Field } \\
\text { Average }\end{array}$ & $\begin{array}{c}\text { Post-Field } \\
\text { Average }\end{array}$ & $\begin{array}{c}\text { Average } \\
\text { Difference }\end{array}$ & $t$ & $S D$ & $P$ & $(n=38)$ \\
\hline Bird & 3.92 & 3.97 & 0.05 & 0.36 & 0.89 & 0.720 & \\
Tree & 3.71 & 3.71 & 0.00 & 0.00 & 1.09 & 1.00 & \\
Salamander & 3.44 & 3.78 & 0.34 & 2.32 & 0.90 & ${ }^{\star} 0.026$ \\
Snake & 2.89 & 3.18 & 0.28 & 1.67 & 1.06 & 0.102 \\
Squirrel & 3.68 & 3.73 & 0.05 & 0.36 & 0.89 & 0.720 \\
Raccoon & 3.57 & 3.68 & 0.10 & 0.61 & 1.06 & 0.544 \\
\hline
\end{tabular}

Note: ${ }^{*} p<0.05$.

and fear was either unnecessary or that it could be overcome. Another key recurring theme was a strong desire on the part of the students to help combat the Biodiversity Crisis, especially amphibian decline.

\section{Discussion}

Some students expressed varying levels of discomfort with herpetofauna. Two subjects refused to even look at preserved museum snake specimens, although students that exhibited milder forms of herpetophobia were for the most part able to step outside of their comfort zones and confront and even overcome much of their nervousness and fear. For this to happen, the students first had to be introduced into the situation that had previously caused them apprehension; the instructor then provided simple encouragement. It should be noted that no one was ever forced to do anything. If a student was truly terrified of frogs, for example, then they were not in any way forced to handle frogs. The conquering of nervousness and fear on the part of the students instead seemed to come about naturally, under the direct supervision of a trained, knowledgeable, and supportive instructor.

What could account for the finding that the participants were more empathetic towards salamanders at the end of the experience versus the beginning? The change in attitude came about in part because of the experience itself and as a function of interacting with Ambystoma opacum. The field participants displayed greater empathy for salamanders, and only for salamanders, the one organism they handled, the one organism to which they were routinely exposed, the one animal they "experienced" firsthand. Experiential learning takes place when the learners personally and directly encounter a subject (Goralnik et al., 2012). In the process, emotional connections are made (Goralnik et al., 2012). These emotional connections produce empathy, among other things. The enhanced ability to feel empathy for and identify with salamanders represents a significant attitude change.

Experiential learning is powerful in that it seeks to enhance the understanding of the learner. Enhanced understanding is achieved through experience and 
emotion and subsequently carries over into the lives and actions of the participant (Goralnik et al., 2012). Interestingly, there was abundant evidence in the journals and in the interview responses that the observed attitude change had carried over into the lives and actions of the study participants. Participants indicated a strong desire to make small changes in their everyday lives, by recycling, by carpooling, by conserving water and energy, etc. Granted, such small changes do not have a significant impact on the Biodiversity Crisis, but the newfound positive attitudes were there nonetheless. Some participants indicated they would be more apt to not kill snakes or otherwise harm herpetofauna. Several likewise indicated a strong desire to "spread the word" by telling others about the Biodiversity Crisis and amphibian decline.

Still, we believe that experience by itself is not enough. For true transformation to occur, students have to reflect upon their experiences (Baker et al., 2012). The role of reflection must be acknowledged. Baker et al. (2012) feel that "teachers must be present and mindful throughout the experiential process in order to guide and direct learning" and that "the role of the teacher is to capitalize upon the experiences [the students] are having and help them reflect ... and make sense of [it all]" (p. 5). During the fall 2012 Conservation of Biodiversity field experience, the instructor was ever-present, and helped the students reflect on their experiences as much as possible by providing expert commentary, essentially managing meaning (Smircich \& Morgan, 1982). All the while, the instructor used the required journal as a tool to promote reflection.

The change brought about in the field participants was therefore most likely due to a dynamic interplay between the instructor, the experience itself, and reflective practice on the part of the students. Any one factor is inadequate when attempting to explain the observed change. All three components are critical, and even then, they must be combined within the confines of the right situation.

Consistent with Kolb (1984), participants actively experienced field work and interacted with charismatic study animals. Study participants were able to reflect on their field experiences and on their interactions with the animals through the required journals. Participants then pieced together how they might act towards amphibians and reptiles in the future; therein lies the attitude change, the conquering of nervousness and fear, and the rise of empathy. Learners then tested their newfound ideas, to some extent in the field and perhaps to some extent after the study was over, as evidenced by their expressed desire to combat the Biodiversity Crisis and amphibian decline, and in their expressed desire to make small changes in their daily lives.

In terms of broader implications, our findings suggest that the utilization of hands-on experiential education in conjunction with reflective practice is a potentially powerful, useful approach for both teachers and natural resource managers as they endeavor to alter the environmental attitudes of students and the general public. Non-game biodiversity does have value, but before individuals can see this value, they must first learn to understand and appreciate the great 
variety of life on planet earth, in all its many forms. A greater understanding and appreciation of non-game biodiversity, including amphibians and reptiles, will then seemingly give way to a desire to conserve these remarkable creatures, or at the very least a willingness to not do them harm.

\section{Conclusion}

In conclusion, non-science majors were able to overcome superficial herpetophobia and even develop greater empathy for salamanders and a greater appreciation for amphibians and reptiles by participating in a real-world amphibian and reptile monitoring project across three successive Saturdays, under the supervision of knowledgeable and supportive instructors. Reflective journaling and reflective practice on the part of the students was a key component in producing the aforementioned attitude change. Some of the study participants will hopefully carry their newfound attitudes throughout the rest of their lives. This will perhaps impact the way they respond to and treat amphibians and reptiles, although admittedly, this will have to be evaluated in a follow-up study.

\section{Acknowledgements}

Support for this project was provided by the University of Tennessee at Chattanooga (UTC), UTC's Think-Achieve Program, UTC's Department of Biology, Geology and Environmental Science, and the Lupton Renaissance Gift Fund. The field portion of this research was conducted in compliance with local, state and federal laws. All research involving animals was permitted by the Tennessee Wildlife Resources Agency and UTC's Institutional Animal Care and Use Committee. All research involving human subjects was approved by UTC's Institutional Review Board. We are grateful to those that have provided comments throughout the project and provided support. We thank the following members of the College of Arts and Sciences: John Tucker, Timothy Gaudin, Ethan Carver, Jose Barbosa, Kelly Locke and Marketa Shutters. We thank other faculty, staff, and students of the UTC community: Hinsdale Bernard, Ted Miller, David Rausch, and Sarah Finley. We thank contributing members of the Team Salamander entity and these include: Mark J. Dillard, Mark D. Wisdom, Brittany Killian, Penni Jo Wilson, Tabitha M. Wilson, Simone Madsen, Robert Altonen, John Burke, Britany Bird, Alicia Courtwright, Stephen A. McCallum, Patricia M. Garland, Rachel M. Head, Nyssa R. Hunt, James A. Kee, Jonathan L. Mason, Ardyce J. Mercier, Fawn M. Revels, Daniel S. Armstrong, Michael J. Bascom, Jessica M. Hubbuch, George W. Szarka, Jennifer L. Nuss, Joseph F. Simpson, and others that we have likely forgotten but appreciate no less.

\section{References}

Alves, R. R. N., Silva, V. N., Trovão, D. M. B. M., Oliveira, J. V., Mourão, J. S., Dias, T. L. P., Alves, A. G. C., Lucena, R. F. P., Barboza, R. R. D., Montenegro, P. F. G. P., Vieira, W. L. S., \& Souto, W. M. S. (2014). Students' Attitudes toward and Knowledge about 
Snakes in the Semiarid Region of Northeastern Brazil. Journal of Ethnobiology and Ethnomedicine, 10, 30. https://doi.org/10.1186/1746-4269-10-30

American Psychiatric Association (2013). Diagnostic and Statistical Manual of Mental Disorders (5th ed.). Washington DC: American Psychiatric Association. https://doi.org/10.1176/appi.books.9780890425596

Baker, M. A., Robinson, J. S., \& Kolb, D. A. (2012). Aligning Kolb's Experiential Learning Theory with a Comprehensive Agricultural Education Model. Journal of Agricultural Education, 53, 1-13. https://doi.org/10.5032/jae.2012.04001

Ballouard, J. M., Provost, G., Barre, D., \& Bonnet, X. (2012). Influence of a Field Trip on the Attitude of Schoolchildren toward Unpopular Organisms: An Experience with Snakes. Journal of Herpetology, 46, 423-428. https://doi.org/10.1670/11-118

Creswell, J. (2007). Qualitative Inquiry and Research Design: Choosing among Five Approaches. Thousand Oaks, CA: SAGE Publications.

Defina, A. V. (1986). Herps in the Field. The American Biology Teacher, 48, 82-84. https://doi.org/10.2307/4448213

Fink, A. (1995). How to Sample in Surveys. Thousand Oaks, CA: Sage Publications, Inc.

Gibbons, W. (1983). Their Blood Runs Cold: Adventures with Reptiles and Amphibians. Tuscaloosa, AL: University of Alabama Press.

Goralnik, L., Millenbah, K. F., Nelson, M. P., \& Thorp, L. (2012). An Environmental Pedagogy of Care: Emotion, Relationships, and Experience in Higher Education Ethics Learning. Journal of Experiential Education, 35, 412-428. https://doi.org/10.1177/105382591203500303

Green, S. B., \& Salkind, N. J. (2008). Using SPSS for Windows and Macintosh: Analyzing and Understanding Data (6th ed.). Upper Saddle River, NJ: Pearson/Prentice Hall.

Hawkins, D. (2014). Biomeasurement: A Student's Guide to Biological Statistics. Oxford: Oxford University Press.

Henry, G. T. (1990). Practical Sampling. Newbury Park, CA: Sage Publications, Inc. https://doi.org/10.4135/9781412985451

Hill, T., \& Lewicki, P. (2006). Statistics: Methods and Applications. Tulsa, OK: StatSoft, Inc. https://doi.org/10.1016/B978-0-323-03707-5.50024-3

Isbell, L. (2009). The Fruit, the Tree, and the Serpent: Why We See So Well. Cambridge, MA: Harvard University Press.

Kolb, D. A. (1984). Experiential Learning: Experience as the Source of Learning and Development. Englewood Cliffs, NJ: Prentice-Hall, Inc.

Makashvili, M., Kaishauri, N., \& Azmaiparashvili, T. (2014). The Role of Knowledge in Overcoming Snake Fear. Procedia-Social and Behavioral Sciences, 152, 184-187. https://doi.org/10.1016/j.sbspro.2014.09.178

Morgan, J. M., \& Gramann, J. H. (1989). Predicting Effectiveness of Wildlife Education Programs: A Study of Students' Attitudes and Knowledge toward Snakes. Wildlife Society Bulletin, 17, 501-509.

Plack, M. M., Driscoll, M., Blissett, S., McKenna, R., \& Plack, T. P. (2004). A Method for Assessing Reflective Journal Writing. Journal of Allied Health, 34, 199-208.

Prokop, P., Özel, M., \& Uşak, M. (2009). Cross-Cultural Comparison of Student Attitudes toward Snakes. Society and Animals, 17, 224-240.

https://doi.org/10.1163/156853009X445398

Schneider, R. L., Krasny, M. E., \& Morreale, S. J. (2001). Hands-on Herpetology: Exploring Ecology and Conservation. Arlington, VA: NSTA Press. 
Smircich, L., \& Morgan, G. (1982). Leadership: The Management of Meaning. In J. L. Pierce, \& J. W. Newstrom (Eds.), Leaders and the Leadership Process: Readings, Self-Assessments and Applications (pp. 23-27). Boston, MA: McGraw Hill.

Tomasek, T., Matthews, C., \& Hall, J. (2005). What's Slithering around on Your School Grounds: Transforming Student Awareness of Reptile and Amphibian Diversity. American Biology Teacher, 67, 419-426. https://doi.org/10.1662/0002-7685(2005)067[0419:WSAOYS]2.0.CO;2

Tomažič, I. (2008). The Influence of Direct Experience on Students' Attitudes to and Knowledge about Amphibians. Acta Biologica Slovenica, 51, 39-49.

Tomažič, I. (2011). Pre-Service Biology Teachers' and Primary School Students’ Attitudes toward and Knowledge about Snakes. Eurasia Journal of Mathematics, Science, \& Technology Education, 7, 161-171. https://doi.org/10.12973/ejmste/75194

Wilson, T. P. (2012). UTC Biological Field Stations [PowerPoint Slides].

Wilson, T. P., Barbosa, J., Carver, E., Reynolds, B. R., Team Salamander, \& Wilson, T. M. (2015). An Assessment of Batrachochytrium dendrobatidis Prevalence in Two Species of Ranid Frogs on a Former United States Department of Defense Installation in Southeastern Tennessee. Herpetological Review, 46, 37-41.

Wilson, T. P., Reynolds, B. R., Wilson, P. J., Bakland, P. E., Hooper, J., Hunt, N., Madsen, S., Cooksey, M., Garland, P., Grigsby, W., Killian, B., Ricks, N., Staundt, L., Taylor, M., Busby, E., Barbosa, J., Carver, E., Armstrong, D., Dillard, M, Simpson, J., Wisdom, M., Wilson, T. M., \& Team Salamander (2017). Team Salamander and Its Evolution in Becoming the Longest Running Group Studies Initiative at the University of Tennessee at Chattanooga. Southeastern Naturalist, 16, 70-93.

https://doi.org/10.1656/058.016.0sp1010 